\title{
Is it correct to perform omentoplasty to repair rectovaginal fistulas in oncological patients?
}

\author{
Antonio Macrì ${ }^{1}$ iD \\ Received: 15 March 2018 / Accepted: 4 May 2018 / Published online: 7 June 2018 \\ ๑) Springer International Publishing AG, part of Springer Nature 2018
}

\section{Dear Sir,}

I read with interest the article by E. Schloericke et al. [1], entitled "Surgical management of complicated rectovaginal fistulas and the role of omentoplasty" published in Techniques in Coloproctology, in which the authors reported their treatment of rectovaginal fistulas in 58 patients, 19 of whom had a history of cancer with a primary localization in the pelvis. There are important considerations to make before transposing the omentum to the pelvis in patients with cancer. As reported in many studies [2], peritoneal carcinomatosis is actually considered a locoregional disease, in which the omentum plays a fundamental role. As reported by Liu [3], invasive peritoneal-exfoliated cancer cells preferentially select the omentum as a predominant target site for cancer cell colonization. Moreover, although the mechanisms underlying peritoneal dissemination have not yet been elucidated, milky spots provide suitable 'soil' for cancer cells to implant [4]. Milky spots, described in 1863 by Recklinghausen as white spots in the omentum of young rabbits [5], and in 1921 by Seifert in the human omentum [6], are lymphatic orifices on the surface of the peritoneum that can be considered as open gates for peritoneal-free cancer cells to migrate into the submesothelial space (3). In the light of these considerations, I think that the transposition of the omentum to the pelvis may potentially increase the incidence of cancer recurrence in patients with a history of cancer, especially cancer of gastrointestinal and ovarian origin, and

Antonio Macrì

amacri@unime.it

1 Peritoneal Surface Malignancy and Soft Tissue Sarcoma Program, Messina University Medical School Hospital, Via Consolare Valeria, 98125 Messina, Italy cannot be recommended in the absence of randomized studies that analyze their oncological outcome.

\section{Compliance with ethical standards}

Conflict of interest The author declares that he has no conflict of interest.

Ethical approval This article does not contain any studies with human participants or animals performed by any of the authors.

Informed consent For this type of study formal consent is not required.

\section{References}

1. Schloericke E, Zimmermann M, Benecke C et al (2017) Surgical management of complicated rectovaginal fistulas and the role of omentoplasty. Tech Coloproctol 21(12):945-952. https://doi. org/10.1007/s10151-017-1657-1

2. Macrì A, Arcoraci V, Belgrano V et al (2014) Short-term outcome of cytoreductive surgery and hyperthermic intraperitoneal chemotherapy: preliminary analysis of a multicentre study. Anticancer Res 34(10):5689-5693

3. Liu J, Geng X, Li Y (2016) Milky spots: omental functional units and hotbeds for peritoneal cancer metastasis. Tumour Biol 37(5):5715-5726

4. Feng S, Feng M, Wenxian Guan (2017) Mechanisms of peritoneal dissemination in gastric cancer (review). Oncol Lett 14:6991-6998

5. Recklinghausen FV (1863) Uber Eiter und Bindesgewebs-korperchen. Vir Arch Pathol Anat 28:157

6. Seifert E (1921) Zur Biologie des menschlichen grossen Netzes. Arch Klin Chir 147:510-517 